\title{
O jogo e a brincadeira na vertente sociointeracionista: uma investigação com professores da educação infantil da rede municipal de ensino em

$$
\text { Gurupi - TO }
$$

\section{Play and game in a methodologic perspective: a research from children education teachers at municipal teaching networking in Gurupi - TO}

Lucilene Gomes da Silva¹, Fernanda Alves de Araújo², Luanna Rodrigues Nogueira ${ }^{3}$.

\section{RESUMO}

Esta pesquisa aborda o tema: jogo e a brincadeira na perspectiva sociointeracionista. E o objetivo foi o de analisar o discurso dos docentes que atuam com turmas de Pré-II da Educação Infantil sobre o jogo e a brincadeira na perspectiva sociointeracionista. Foi realizada em seis instituições escolares da rede municipal de ensino que oferece Educação Infantil em tempo integral, classifica-se como um estudo de campo, do tipo exploratório e descritivo, de natureza qualitativa. A amostra da pesquisa foi composta por onze professores regentes das turmas de Pré Alfabetização II. Para levantamento dos dados foi utilizada uma entrevista estruturada, contendo uma questão geradora. A análise das informações foi baseada na técnica de análise de conteúdo, elaborada por Moreira; Simões \& Porto (2005), designada como: Análise de Conteúdo: técnica de elaboração e análise das unidades de significados. O estudo permitiu identificar visões muito comuns de que o jogo e a brincadeira contribuem para a socialização da criança, de modo a torná-la mais independente, autônoma, criativa, cooperativa. Além disso, foi possível conhecer também o discurso com concepções atreladas ao brincar e ao jogar nas visões desenvolvimentistas e psicomotoras as quais indicam que este momento é favorável para o desenvolvimento cognitivo, concepções estas que não coadunam com a vertente sociointeracionista..

Palavras-chave: Educação Infantil. Sociointeracionismo. Jogos e brincadeiras.

\section{ABSTRACT}

This research has as a theme: play and game in a methodologic perspective. And it has had as an objective to analyze the teachers' lectures who work with early children in primary education about play and game in a methodologic perspective. The research was accomplished is six schools at the municipal networking education that offers full time classes, it is classified as a field study, exploratory, descriptive, and qualitative types. The samples of this research were through eleven teachers from kindergarten classes. It was used as an interview as an instrument of data. The analysis of the information was based on the technique of content analysis, and it was elaborated by Moreira; Simões \& Porto (2005), it was designated as: Content analysis: technique elaboration, technique and analysis of the units. This study allowed us to identify how the play and the game can contribute to the child socialization, which can make it more independent, autonomous, creative and helpful. In addition, it was possible to know the opinion about some concepts linked to: play and game in developmental and psychomotor visions which has shown that this moment is favorable for the cognitive development, conceptions that do not co-exist with the methodologic perspective.

Keywords: Early Childhood Education, methodologic perspective, plays and Games.
${ }^{1}$ Professora Mestre em Educação Física, coordenadora do projeto de pesquisa. Universidade de Gurupi- UnirG.

E-mail: lucilenegs@yahoo.com.br.

${ }^{2}$ Acadêmica voluntária do projeto de pesquisa. Universidade de Gurupi- UnirG.

${ }^{3}$ Acadêmica voluntária do projeto de pesquisa. Universidade de Gurupi- UnirG. 


\section{INTRODUÇAOO}

A Lei de Diretrizes e Bases da Educação Nacional Brasileira (LDB), lei de oㅡ 9394/96, define Educação Infantil no artigo 29 como a primeira etapa da educação básica, a qual tem como finalidade o desenvolvimento integral da criança até seis anos de idade em seus aspectos físico, psicológico, intelectual e social, completando a ação da família e da comunidade. E esta, de acordo com o artigo 30, é ofertada em: I - creches, ou entidades equivalentes, para crianças de até três anos de idade; II - pré-escolas, para crianças de quatro a seis anos de idade.

Na cidade de Gurupi - TO a Educação Infantil pública encontra-se em consonância com o que é previsto pela legislação nacional, organizada da seguinte maneira: Creche: Berçário I - Berçário II - Maternal I - Maternal II -; Pré-Escola: Pré I - Pré II - E são ofertadas em: um Instituto educacional; oito escolas regulares; três instituições filantrópicas e três centros municipais de educação infantil (CEMEIS) (TOCANTINS, 2013).

Com a crescente demanda na oferta da Educação Infantil pública na cidade de Gurupi- TO, a Secretaria Municipal de Educação no ano de 2013 elabora uma Proposta Curricular para orientar o trabalho dos professores que atuam nesse segmento escolar. Esta proposta alinha-se com as orientações e princípios do Referencial Curricular Nacional para Educação Infantil.

Sendo assim, a proposta apresenta as orientações necessárias para a atuação do professor nas ações de educar e cuidar. Dentre todas as orientações destaca-se a organização curricular por ser um dos focos de interesse da presente pesquisa.

$\mathrm{Na}$ organização curricular é previsto o trabalho a partir de dois eixos: Formação Pessoal e Social e o Conhecimento de Mundo, os quais se subdividem em: Identidade e Autonomia; Movimento; Música; Artes Visuais; Linguagem Oral e Escrita; Natureza e Sociedade e Matemática.

Evidencia-se especificamente o eixo movimento, por ser alvo de estudo da presente pesquisa. Este eixo de acordo com a Proposta Curricular para a Educação Infantil da Rede Municipal de Educação de Gurupi (2013) possui valor de distinta relevância e serve para a criança se relacionar com o outro, explorar espaço, situando-se nele, bem como os objetos e o próprio corpo.

Uma das formas de materialização da vivência do movimento na Educação Infantil encontra-se no ato de brincar e jogar. A brincadeira de acordo com a presente proposta é 
compreendida: "como uma atividade humana na qual as crianças são introduzidas, constituindo, um modo de assimilar e recriar as experiências socioculturais dos adultos" (TOCANTINS, 2013.p. 57).

A brincadeira e o jogo são apontados ao longo do item orientações de atividades para cada eixo e etapa educacional como sugestões favoráveis para o alcance do subeixo Movimento. No entanto, o que mais chamou a atenção e despertou para a investigação sobre o presente tema foi adoção da perspectiva sociointeracionista de Vygotsky como princípio balizador das ações didáticas dos professores.

A partir do sociointeracionismo a proposta curricular para as escolas infantis municipais de Gurupi- TO compreende a criança como um sujeito histórico social e um ser competente para interagir e produzir cultura no meio em que se encontra. Defendem a interação social como espaço de constituição e desenvolvimento da consciência do ser humano desde que nasce.

Diante do que foi exposto acerca da proposta curricular para Educação infantil, sobre o eixo movimento, brincar e jogar e sobre os princípios balizadores pautados no sociointeracionismo surgiram algumas inquietações que se configurou enquanto problemática da pesquisa: Como seria o discurso das professoras que atuam no Pré II ao aplicar os jogos e as brincadeiras a partir da proposta sóciointeracionista?

Diante disso, tem-se como hipótese do trabalho, que mesmo diante do que vem estabelecido pela proposta curricular da Secretaria Municipal de Educação de Gurupi- TO, enquanto princípios metodológicos sociointeracionista, o discurso sobre jogos e brincadeiras adotadas pelas professoras que atuam com as turmas de Pré Il encontra-se sob a influência das vertentes recreacionistas e psicomotoras.

E o objetivo do trabalho foi o de analisar o discurso dos docentes que atuam com turmas de Pré-Il da Educação Infantil sobre o jogo e a brincadeira na perspectiva sociointeracionista.

O estudo permitiu identificar visões muito comuns de que o jogo e a brincadeira contribuem para a socialização da criança, a torná-la mais independente, autônoma, criativa, cooperativa. E que por meio dos jogos e das brincadeiras as crianças podem compreender mais o processo educativo e assim, haver uma aprendizagem significativa.

Além disso, foi possível conhecer o discurso com concepções atreladas ao brincar e ao jogar muito presente nas visões desenvolvimentistas e psicomotoras de que este momento é favorável para o desenvolvimento cognitivo. 


\section{O Jogo e a Brincadeira na Pré-Escola}

Para analisar as contribuições do jogo e da brincadeira para o desenvolvimento e aprendizagem da criança se faz necessário conhecer e apresentar algumas compreensões que estes possuíram ao longo da história da humanidade.

A autora Wajskop (2001) mostra que a compreensão de jogo e brincadeira está associada à compreensão de que se tem de criança, esta influencia na forma de se conduzi-los no ambiente educacional. As ideias de Rousseau permitiu que se criassem inúmeros brinquedos educativos utilizando princípios da educação sensorial.

Friedrich Froebel, Maria Montessori e Ovide Decroly foram os primeiros pedagogos da educação pré-escolar a romper com a visão tradicional e verbal da época. "Propuseram uma educação sensorial, baseada na utilização de jogos e materiais didáticos, que deveriam traduzir por si a crença em uma educação natural dos instintos infantis" (WAJASKOP, 2001, p. 22).

Kishimoto (2001) fala que antes da revolução romântica, três concepções de jogo e brincadeira se fazia muito presente na época. São elas: a recreação, o uso do jogo para favorecer o ensino de conteúdos escolares, diagnóstico da personalidade infantil como recurso para ajustar o ensino às necessidades infantis.

Wajaskop (2001, p.23) enfatiza ainda que: "os pensamentos froebelianos, montessoriano e decrolyano têm-se transformado principalmente após os anos 70, com a priorização dos programas de educação compensatória, em meros instrumentos didáticos."

A autora ainda mostra que nesse período a maioria das escolas tem didatizado as atividades lúdicas das crianças restringindo a exercícios repetitivos de discriminação viso motora e auditiva, através de brinquedos, desenhos coloridos, mimeografados e músicas ritmadas (WAJASKOP, 2001).

Kishimoto (2001) aponta que o jogo é visto nas ideias de Groos como algo natural, biológico, necessário para a espécie para o treino de instintos herdado. O jogo como ação espontânea, prazerosa e livre já antecipa sua relação com a educação.

A brincadeira como atividade controlada pelo professor é posta como algo sedutora para criança. Neste tipo de brincadeiras as crianças não possuem a iniciativa de definirem nem o tema, nem os papéis, nem os conteúdos e o seu desenvolvimento. $O$ controle pertence ao adulto e este usa o interesse da criança pela brincadeira para despistá-lo em função dos objetivos educacionais (WAJASKOP, 2001). 


\section{O jogo e a brincadeira na perspectiva sociointeracionista}

Partindo da premissa de que a criança desde o seu nascimento encontra-se inserida no contexto social foi que autores propuseram outros olhares para o jogar e brincar da criança. Dessa forma, a brincadeira passa a ser uma atividade humana na qual as crianças são introduzidas e torna-se uma forma de conhecer e recriar sua experiência sócio- cultural junto com os adultos (WAJASKOP,2001).

A brincadeira nesta vertente educacional é compreendida como uma atividade social específica e fundamental para garantir a interação e construção de conhecimento e da realidade. A brincadeira é o resultado de relações interindividuais, portanto de cultura. A brincadeira pressupõe uma aprendizagem social. Aprende-se a brincar (BROUGÈRE, 1997).

Na concepção sócio- cultural a brincadeira segundo Brougère (1997) é vista como uma mutação de sentidos da realidade. É um espaço paralelo à vida comum que obedece a regras provindas do contexto social e cultural, os objetos recebem significados e sentidos para além daquilo que eles representam e os comportamentos são idênticos aos da vida cotidiana.

Rego (1995) traz a compreensão de Vygotsky acerca do ato de brincar, para o autor este ato também pode ser chamado de brinquedo. $O$ qual especificamente dedicou seus estudos aos brinquedos de faz-de-conta ou de papéis, os do tipo brincar de médico, vendinha, mãe-filha, médico e polícia-ladrão.

Através desse tipo de brincadeiras a criança para Vygotsky aprende atuar numa esfera cognitiva que depende de motivações internas, é capaz de fazer a diferenciação entre o que vê e o seu significado e faz uso da representação (REGO, 1995).

A criança passa a criar uma situação ilusória e imaginária, como forma de satisfazer seus desejos não realizáveis. Esta é, aliás, a característica que define o brinquedo de um modo geral. A criança brinca pela necessidade de agir em relação ao mundo mais amplo dos adultos e não apenas ao universo dos objetos a que ela tem acesso. (REGO, 1995, p.82)

$\mathrm{Na}$ brincadeira infantil, organizada de forma independente do adulto, as crianças podem exercer sua posição social e recriar os ambientes sociais aos quais estão inseridas, aprender tomar decisões, a confrontar pontos de vista diferentes dos seus e construir relações. 
Sobre as brincadeiras de faz-de-conta Wajaskop (2001) a classifica como brincadeiras de papéis em que as crianças assumem a protagonização, em que revelam e possibilitam ao mesmo tempo o desenvolvimento de regras e da imaginação por meio dos gestos e ações significativas.

Por fim, a brincadeira é uma situação privilegiada de aprendizagem infantil em que o desenvolvimento pode alcançar níveis mais complexos, exatamente pela possibilidade de interação entre os pares em uma situação imaginária e pela negociação de regras de convivência e de conteúdos (WAJASKOP, 2001).

\section{MATERIAIS E METODOS}

Este estudo se classificou como exploratório e descritivo de acordo com Mattos; Rossetto Jr e Blecher (2004). A abordagem foi do tipo qualitativa de acordo com Minayo (2001).

A pesquisa foi desenvolvida no universo de seis instituições que oferecem a Educação Infantil na Rede Pública Municipal de Gurupi- TO, especificadamente as que ofertam a modalidade de tempo integral e que possuíam turmas para o Pré- alfabetização II. Os sujeitos que participaram da pesquisa foram onze professoras.

Essa pesquisa seguiu todas as orientações da Resolução 466/ 2012 CNS (Conselho Nacional de Saúde) sobre pesquisas que envolvem seres humanos, a qual foi aprovada pelo Comitê de Ética e Pesquisa da Universidade de Gurupi- UnirG, sob o parecer de número: 2.113.140.

Para coleta das informações a campo utilizou a entrevista estruturada para o momento de obter o discurso dos sujeitos envolvidos. E para a concretização desta utilizamos de recurso de gravador de áudio.

A questão geradora que compôs a entrevista estruturada foi: Professora, para você quais são as contribuições do ensino dos jogos e brincadeiras para o desenvolvimento e aprendizagem da criança na vertente sociointeracionista?

A análise das informações foi baseada na técnica de análise de conteúdo, elaborada por Moreira; Simões e Porto (2005), designada como: Análise de Conteúdo: técnica de elaboração e análise das unidades de significados. 


\section{RESULTADOS}

Tabela 1 referente à questão: Professora, para você quais são as contribuições do ensino dos jogos e brincadeiras para o desenvolvimento e aprendizagem da criança na vertente sociointeracionista?

\begin{tabular}{|c|c|c|c|c|c|c|c|c|c|c|c|}
\hline UNIDADES DE SIGNIFICADO & S1 & S2 & S3 & S4 & S5 & S6 & S7 & S8 & S9 & $\mathrm{S} 10$ & $\mathrm{~S} 11$ \\
\hline $\begin{array}{l}\text { 1. A conviver com o outro e } \\
\text { socializar. }\end{array}$ & $x$ & & $x$ & & & $x$ & & $x$ & & $x$ & \\
\hline $\begin{array}{l}\text { 2. A ser mais independente- } \\
\text { seguro e com maturidade. }\end{array}$ & $x$ & & & & & $x$ & & & & & \\
\hline $\begin{array}{l}\text { 3. Deixar a criança mais feliz- } \\
\text { à vontade - criativa e } \\
\text { lúdica. }\end{array}$ & & $x$ & $x$ & $x$ & & & & & & & \\
\hline $\begin{array}{l}\text { 4. Aprender brincando e com } \\
\text { mais significado. }\end{array}$ & & & $x$ & & & $x$ & $x$ & & & & \\
\hline 5. Desenvolver a cognição. & & & & & & $x$ & & & $x$ & & \\
\hline $\begin{array}{l}\text { 6. A ter resultados } \\
\text { satisfatórios. }\end{array}$ & & & & & $x$ & & & & & & \\
\hline $\begin{array}{l}\text { 7. Desenvolver os aspectos } \\
\text { motores. }\end{array}$ & & & & & & & & & & & $x$ \\
\hline
\end{tabular}

\section{DISCUSSÃO}

Iniciando pela unidade de significado número 1: $\underline{\text { A conviver com o outro e socializar }}$ a qual teve 5 das 11 entrevistadas, que foram S1, S3, S6, S8 e S10. Essa é uma visão muito comum ao se tratar dos benefícios e contribuições que o jogo possui na Educação Infantil, visão essa coerente com o pensamento sociointeracionista.

A corrente de pensamento sociointeracionista advoga que o conhecimento é adquirido por meio das interações que os sujeitos estabelecem com os outros e com o mundo e estas acontecem calcadas por meio das experiências (MACHADO, 1999). Assim, analisando que a aquisição do conhecimento na etapa escolar infantil deve ser valorizada por meio das atividades lúdicas, o jogo e a brincadeira são veículos muito utilizados para levar à criança esse conhecimento. Nesse sentido, Wajaskop (2001) coloca que a brincadeira tem um papel educativo valoroso nessa etapa educacional da infância, pois permite que as crianças vão conhecendo o mundo ao mesmo tempo em que se desenvolvem, criando intercâmbios sociais a partir das diferentes histórias de vida das crianças, dos pais e dos professores atores sociais, que cotidianamente se fazem presentes nesse espaço educativo.

Nas palavras de Wajaskop (2001) a brincadeira é um elemento social favorável para a interação infantil a qual pode contribuir na constituição da criança como sujeito humano produto e produtor de história e cultura. A partir do exposto, os discursos dessas 
cinco professoras que compreendem que ao brincar as crianças se socializam e logo aprendem a conviver com o outro estão coerentes com o que é preconizado pela corrente sociointeracionista.

A unidade de significado 2. A ser mais independente- seguro e com maturidade; teve apenas dois sujeitos S1 e S6. É o que nos diz: S1 "...aprender até mesmo é é ser mais independente. Aprender dizer sim e não a ter opiniões, eu quero é esse, esse eu não quero né." E S6 "eu acredito que com os jogos ele vem a se sentir muito mais tranquila muito mais segura, ele vai pegando aquela segurança ele vai tendo adquirindo cada etapa vai adquirindo maturidade."

A visão expressa por essas professoras remete justamente aos princípios sociointeracionista para a Educação Infantil, em que o brincar é elemento fundamental no processo educativo, sobre essa visão Wajaskop (2001) destaca que a brincadeira é um espaço privilegiado de interação e confronto de diferentes crianças com diferentes pontos de vista. E na vivência desses conflitos as crianças podem enriquecer a relação com seus pares, adquirindo autonomia e cooperação podendo assim, agir na realidade de forma ativa e construtiva.

A unidade de significado 3 . Deixar a criança mais feliz- à vontade - criativa e lúdica; teve três professoras S2, S3 e S4. Essa é uma concepção clássica de se compreender o processo educativo pela via do sociointeracionismo em que a brincadeira é fonte constituinte nesse processo, sobre essa concepção expressa pelas professoras, Wajaskop (2001) coloca que a brincadeira se constitui como o espaço que fornece a possibilidade de construção de uma identidade infantil autônoma, cooperativa e criativa.

4. Aprender brincando e com mais significado; É uma unidade de significado em que apresentou as professoras S3, S6 e S7 compreendendo que a contribuição que os jogos e as brincadeiras podem possibilitar em uma visão sociointeracionista é de ao brincar e jogar as crianças compreende mais o processo educativo e assim há uma aprendizagem significativa. Na brincadeira a criança adota um comportamento que de acordo com Wajaskop (2001) é um comportamento social, e neste a criança adquire novos significados para as suas ações.

A unidade de significado 5 . Desenvolver a cognição; foi elaborada para aglutinar o pensamento de duas professoras S6 e S9. Essa concepção de desenvolvimento intelectual/ cognitivo atrelada ao brincar é muito presente em várias correntes educacionais, aqui estamos considerando coerente o ponto de vista dessas professoras na perspectiva sociointeracionista, uma vez que, nessa vertente o brincar é compreendido 
como um espaço social, em que há trocas constantes entre os sujeitos que se relacionam e nesse ato há sim uma possibilidade de desenvolvimento cognitivo e intelectual, embora, ressaltamos que para isso acontecer há que se tomar o cuidado com o excesso de instrumentalização da brincadeira e do jogo, porque se assim não, o fizerem essa ideia expressa pelas professoras estariam vinculada as vertentes educacionais psicomotoras e desenvolvimentistas, o que estaria em desacordo com os questionamentos do presente estudo.

Nas unidades de significados: $\underline{6}$. A ter resultados satisfatórios. E $\underline{7}$. Desenvolver os aspectos motores. Apresentou apenas um sujeito em cada uma delas, especificadamente na unidade 6 tivemos o sujeito S5 e na unidade 7 o sujeito S11. Estas serão analisadas conjuntamente, pois, a ideia expressa por estas professoras não coadunam com a vertente sociointeracionista, nessa vertente não se busca a ter resultados satisfatórios e tão pouco objetiva o desenvolvimento de aspectos motores.

Nas palavras de S5: "Então, muitas vezes é a ludicidade de um jogo de uma brincadeira nós podemos alcançar um resultado bem melhor mais satisfatório para desenvolver uma, para introduzir um conteúdo de livro ao passo que podemos desenvolver dentro da sala nós podemos desenvolver e introduzir através de um jogo de uma brincadeira e o resultado será alcançado com melhor satisfação."

E nas palavras de S11: "Então é..é.. contribui de uma forma geral tanto no ensino e aprendizagem quanto no desenvolvimento dele assim, como eu diria. assim... motor de uma forma geral a gente procura trabalhar de forma interdisciplinar né encaixando assim."

Essas duas visões preocupam, isso porque em seus discursos o que foi realmente possível de se abstrair foi essa visão de que os jogos e brincadeiras contribuem para o desenvolvimento dos aspectos motores. E no discurso de S5 a ideia de rendimento, resultado satisfatório. Não que estes, não venham a contribuir, pois sabemos sim que o ato motor, a vida de movimento possibilitada pelos jogos e brincadeiras podem e muito ajustar funções psicomotoras, como lateralidade, coordenação motora, noção de espaço e tempo, dentre outras. Como também a instrumentalização dos jogos e das brincadeiras pode contribuir com uma aprendizagem significativa, como já foi analisada anteriormente a opinião das outras professoras.

O que se ressalta e que chamou a atenção foram essas concepções das professoras associada a vertente sociointeracionista. Vertente essa, que baliza toda a proposta educacional da rede municipal de Gurupi- TO. 


\section{CONSIDERAÇOES FINAIS}

O presente estudo possibilitou conhecer o discurso dos docentes que atuam com turmas de Pré-Alfabetização II na rede municipal de ensino de Gurupi-TO, sobre o jogo e a brincadeira na vertente sociointeracionista. A análise dos discursos das onze professoras entrevistadas permitiu identificar no discurso destas visões muito comuns de que o jogo e a brincadeira contribuem para a socialização da criança, a torná-la mais independente, autônoma, criativa, cooperativa. $E$ que por meio dos jogos e das brincadeiras as crianças podem compreender mais o processo educativo e assim, haver uma aprendizagem significativa.

Além disso, foi possível conhecer o discurso com concepções atreladas ao brincar e ao jogar muito presente nas visões desenvolvimentistas e psicomotoras de que este momento é favorável para o desenvolvimento cognitivo. Como também o discurso de que quando as crianças jogam e brincam elas têm resultados melhores e também uma melhora motora, concepções estas que não combinam com a vertente sociointeracionista.

Constata-se ao final desse trabalho que a hipótese levantada inicialmente foi em partes confirmada. Isso, porque ainda é possível perceber no discurso das professoras a visão do jogo e da brincadeira na perspectiva psicomotora. No entanto, a concepção recreacionista não apareceu nos discursos e a predominância da compreensão do jogo e da brincadeira para o processo de desenvolvimento e aprendizagem da criança está de acordo com a corrente de pensamento sociointeracionista, concepção norteadora da proposta educacional da rede municipal.

Indica-se que novas pesquisas possam ser implementadas nesse mesmo contexto, a fim de construir um diagnóstico da aplicação da vertente sociointeracionista na Educação Infantil, porém agora com um reconhecimento in locu da prática dessas professoras na aplicação dos jogos e brincadeiras no momento do eixo movimento.

\section{REFERÉNCIAS}

BRASIL, Ministério da Educação e do Desporto. Secretaria da Educação Fundamental. Referencial Curricular Nacional para a Educação Infantil. Brasília, 1998.

BROUGÈRE, G. Brinquedo e cultura. Revisão técnica e versão brasileira adaptada por Gisela Wajaskop. 2ª̀ed. São Paulo: Cortez, 1997.

KISHIMOTO, T. M. Jogos, brinquedo, brincadeira e a educação. (Org) 4⿳亠丷a ed. São Paulo: Cortez, 2001. 
MACHADO, M. L de A. Educação Infantil e Sócio-Interacionismo. In: OLIVEIRA, Zilma Moraes Ramos de (org.). Educação Infantil: muitos olhares. 2 ed. São Paulo: Cortez, 1995.

MOREIRA, W. W.; SIMOES, R.; PORTO, E. Análise de conteúdos técnicas de elaboração e análise de significados. Revista brasileira Ciência e Movimento. 13(4). p. 107-114, 2005.

TOCANTINS, Secretaria Municipal de Educação. Proposta Curricular para a Educação Infantil. Gurupi: SME, 2013.

REGO, T. C. Vygotsky. Uma perspectiva histórico-cultural da educação. Petrópolis: Vozes, 1995.

WAJASKOP, G. Brincar na pré-escola. 4ª̣ ed. São Paulo: Cortez, 2001.

\section{AGRADECIMETNO}

Agradecemos à Universidade de Gurupi, pelo apoio proporcionado através do edital Projetos de Pesquisa E Inovação/ Edital PROPESQ/SPPI № 01/2016. 